\title{
Toxic Shock Syndrome and Tampons: The Birth of a Movement and a Research 'Vagenda'
}

\author{
Nancy King Reame
}

\section{Toxic Shock Syndrome and Tampons: \\ The Birth of a Movement}

Long before 2015 was lauded by the mainstream media as "the year of the Period," the menstrual health movement was launched, in part, by the discovery in 1980 that tampons were linked to some 800 cases of severe illness and 20 deaths caused by the made-in-America tragedy of Toxic Shock Syndrome (TSS) (Shands et al. 1980). Menstrual TSS (mTSS) is a severe, life-threatening bacterial infection that gives rise to flu-like symptoms early on, but rapidly escalates to falling blood pressure, organ failure, and death (5-10\% mortality) if not recognized in time (Reingold et al. 1982). For those who recover, morbidity is high with a $30 \%$ recurrence rate (Hajjeh et al. 1999) (Fig. 51.1).

Once the connection between tampons and TSS was exposed, it became clear to the Food and Drug Administration (FDA) and tampon producers that a huge gap existed in their understanding of how menses interacted with the vaginal environment. In the public domain, prospective studies had yet to be done examining how menses degraded during its absorption by what was considered at the time to be an "inert" feminine hygiene product, and research on the basic elements of menses was relatively rare. The limited

This paper is dedicated to the memory of Esther Rome, co-founder of the Boston Women's Health Book Collective and one of the original authors of Our Bodies, Ourselves. Not only a leading women's health activist, she was a true pioneer in the menstrual health movement. 
number of studies available were mostly related to abnormal uterine bleeding and postpartum hemorrhage in obstetric patients. All we knew about the role of tampons in TSS was based on the Centers for Disease Control (CDC) reports and phone interviews with victims after the fact. No wonder the industry and the public health world were blindsided by TSS.

As a newly minted $\mathrm{PhD}$ in reproductive physiology and former $\mathrm{OB}$ nurse, I was becoming involved in menstruation research. I had received a $\$ 25,000$ grant from Kimberly-Clark Corporation, makers of Kotex products, to conduct a study of menstrual fluid components and flow characteristics as a preliminary step in their development of a synthetic menstrual fluid that could be used for testing product absorbency. At the time, the industry standard was blue-dyed saline.

I wondered why such a straightforward study could not have been accomplished "in-house." When I visited Kimberly-Clark headquarters to deliver my findings, I learned that most corporate scientists (besides being all male) were trained as paper chemists; they started their research and development $(\mathrm{R} \& \mathrm{D})$ careers in the "feminine hygiene" product line before progressing to more prestigious divisions such as Kleenex and paper towels. The social stigma of menses and its products appeared to be entrenched even in the tampon industry. Chris Bobel would later refer to such period shaming as

Fig. 51.1 Nancy

Reame with the Syngina she used in her study of tampon absorbency (circa 1982) (Credit: Advance Magazine/ Peter Yates c.1982. Used with the permission of Michigan Medicine)

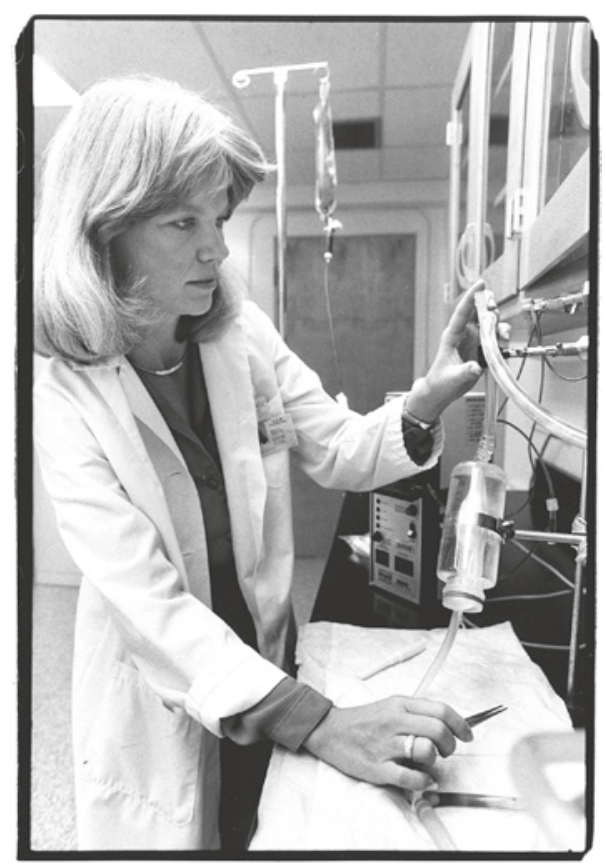


evidence of "disgust directed at the female body" (2018). Undoubtedly, this bias shaped both industrial and federal responses to the TSS epidemic.

As tampon makers rushed to mount an all-out defense of their brands against wrongful death lawsuits, ${ }^{1}$ there was public outcry for the federal government to improve oversight of tampon production. Consumers wanted guidance from the CDC on choosing the lowest absorbency size of tampons in order to avoid mTSS. Without a comparative labeling guide on every box, women had no way of knowing how one company's "regular" compared to another company's "super."

Under mounting public pressure, in 1982 the FDA requested that the American Society for Testing of Materials (an independent medical device research society that develops consensus guidelines) convene a Task Force composed of representatives from each tampon company, consumer organizations, and women's health advocacy groups. The goal was to build a set of Federal standards for tampon absorbency ranges and nomenclature similar to those established for sunscreen products, as well as industry-wide testing procedures for tampon safety. As a start, each company agreed to undertake a series of laboratory tests anonymously comparing each other's products to determine, for the first time, how absorbency ranked across brands. ${ }^{2}$

As one of the few nonindustry researchers who had actually worked with menses, I was opportunely positioned to serve as the scientific consultant for the consumer groups on the Task Force and to conduct identical testing in our university labs. The FDA protocol called for the use of the "Syngina" (synthetic vagina) test to measure absorbency of all the products of US tampon makers, which were provided in a blinded fashion by the FDA to each lab.

The Syngina method (Fig. 51.2) specifies a test procedure and test fluid for the laboratory measurement of the absorbency of menstrual tampons. Considered the gold standard by the tampon industry worldwide even today, it is used in production sites for quality control and ensuring compliance with FDA regulations. Designed to simulate body temperature, vaginal pressure, and flow rates, the Syngina apparatus introduces defined amounts of test fluid (the blue saline solution) until the tampon leaks. The tampon weight is taken before and after the test to calculate the weight in grams of fluid absorbed.

To make ours a meaningful study, I assumed we would not only use the standard test fluid, but also conduct comparative studies with menstrual blood, given the stark differences in their chemical and physical properties (not to mention the color!). Here was an opportunity to gain valuable information that might shed light on basic tampon-menses interactions under controlled conditions. But I knew the industry folks would poo-poo this idea based on its presumed variability in composition from day-to-day and woman to woman, ${ }^{3}$ not to mention the likelihood that the apparatus and flow rates would have to be recalibrated, given the differences in viscosity. 


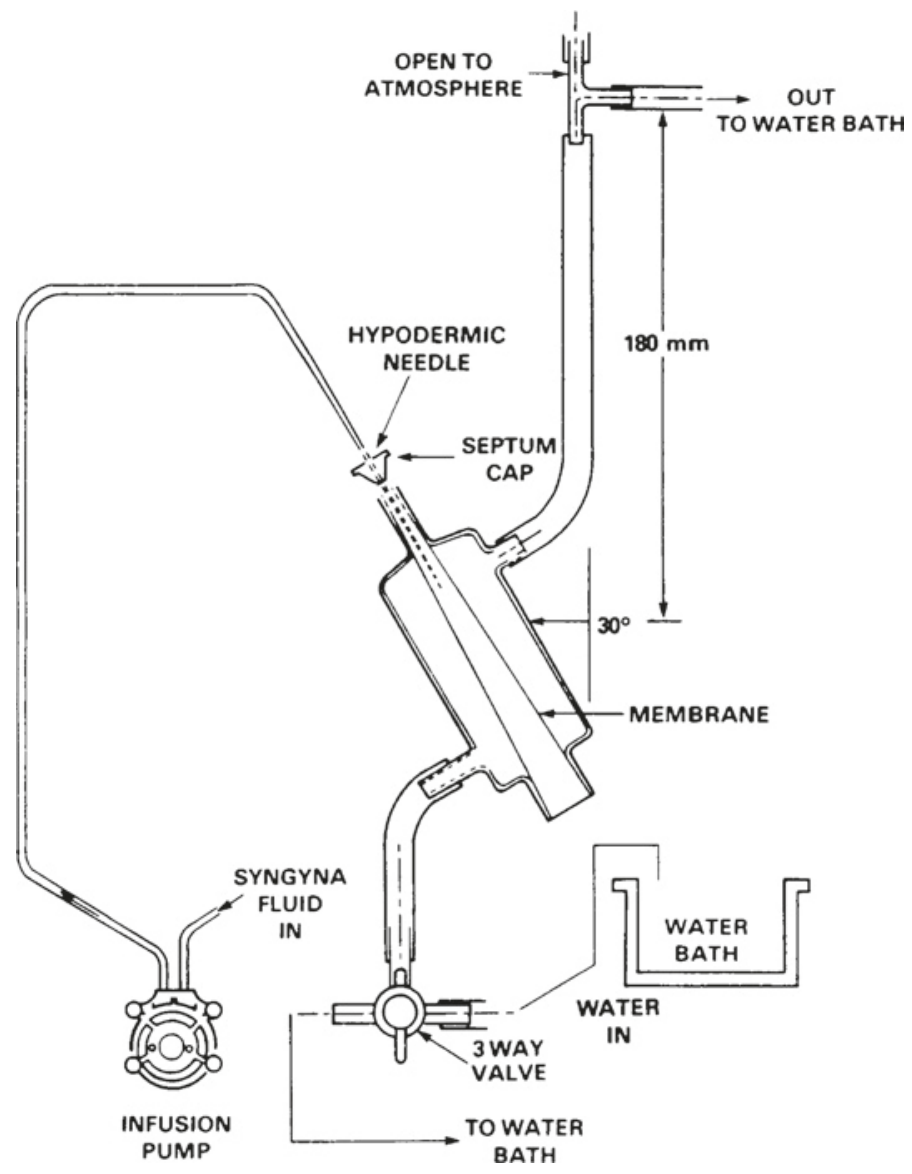

Fig. 51.2 The Syngina test instrument: The industry standard for measuring tampon absorbency (Source Code of Federal Regulations Title 21, Volume 8 (2018), figure 2, accessed March 1, 2018, https://accessdata.fda.gov/scripts/cdrh/cfdocs/ cfCFR/CFRSearch.cfm?fr-801.430. Credit: The US Food and Drug Administration [FDA] 2018)

As a compromise, I proposed using the next best thing: outdated heparinized blood from the hospital blood bank. Here was a test solution easily obtainable by all the labs and much more uniform in its consistency, yet similar to menses in its de-clottable state. Industry members of the Task Force emphatically refused this suggestion based on the presumption that the blood would be too viscous and would clog up the machine.

With the full support of the consumer groups and women's health advocates on the Task Force, our all-woman $\mathrm{lab}^{4}$ at the University of Michigan 
Children's Hospital (thank you Dr. Robert Kelch, Chair of Pediatrics) went ahead as the sole study site to perform the Syngina tests using both salt water and venous blood. We discovered that our results were consistent, easily reproducible, and demonstrated marked differences across all brands and absorbency categories (junior, regular, super, and super plus). In both cases, the test clearly documented what the CDC had already shown: one brand's "regular" was more absorbent than another's "super." But, most importantly, in all cases the absorbency of the surrogate menstrual fluid exceeded that of the blood-free test fluid, especially for the superabsorbent brands (Reame, Delonis, and Lewis 1987).

Years later, this early "menstrual moment" would be described by Vostral $(2017 \mathrm{~b})$ as an example of feminist science challenging the industry practice of deconstructing the flesh and blood of the human vagina to simulate the "biological materiality of menstruating bodies" with a Syngina device and salt water. In the 1980s and just starting my career in women's health, I wouldn't have recognized the term "feminist science." I just knew, as a nurse and a menstruating woman, that comparing salt water to blood simply made good sense.

I submitted my final report to the National Consumers' League in 1983 (Reame 1983). But it remained confidential for several years as the Task Force became polarized about how best to formulate a labeling standard that would satisfy the competing needs of tampon makers while addressing the concerns of consumer groups. After the Task Force disbanded in 1985, the lack of transparency about the absorbency guidelines, as well as the FDA's failure to require independent research or the listing of all tampon ingredients, served as stinging reminders of how much more work was left to be done. Sadly, our demands for the release of industry testing data for such properties as shredding, string strength, and contaminants remained unaddressed. Moreover, follow-up attempts by menstrual activists to sustain national interest in mTSS and the need for greater consumer protections were met with inconsistent attention by the media. As a way to make the broader medical world aware of the basic flaws in the proposed federal standard, a group of us wrote up a summary of my findings as a Letter to the Editor of the Journal of the American Medical Association in 1988 (Rome, Wolhandler, and Reame 1988).

In 1990, the demands of the Task Force's women's health activists and consumer members were ultimately achieved, in part, with the establishment of a comparative numbering system for absorbency across all brands (Table 51.1). However, there would never be any mention on package labeling that the laboratory test fluid was blue-dyed saline. Women would falsely assume that the chart depicting the ranges of absorbency for light, regular, super, and super plus referred to grams of menstrual fluid, not grams of salt water. Thus, they would underestimate the true physiologic conditions of the 
Table 51.1 FDA-required absorbency ranges for labeling of tampon products sold in the US

\begin{tabular}{ll}
\hline Ranges of absorbency in grams $^{a}$ & Corresponding term \\
\hline 6 and under & Light absorbency \\
Greater than 6-9 & Regular absorbency \\
Greater than 9-2 & Super absorbency \\
Greater than 12-15 & Super plus absorbency \\
Greater than 15-8 & Ultra absorbency \\
Above 18 & No term \\
\hline
\end{tabular}

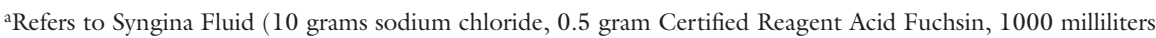
distilled water)

Source Data adapted from sec. 801.430 User labeling for menstrual tampons, Code of Federal Regulation, Title 21, Vol. 8 (2018), sec. 801.430, accessed March 1, 2019, https://www.accessdata.fda.gov/scripts/cdrh/ cfdocs /cfCFR/CFRSearch.cfm? fr $=801.430$

Credit: Nancy Reame

tampon-vaginal environment with normal wear-one of the many omissions that persists due to gaps in assessment protocols, regulatory oversight, and common practices of the tampon industry today.

\section{Contemporary Period Products, Regulations, and Manufacturing Practices}

\section{The Regulated Tampon: Or Is It?}

Although there are still no federal laws requiring manufacturers' universal disclosure of tampon (or pad) ingredients or by-products, ${ }^{5}$ most tampon producers, under pressure from menstrual activists, now voluntarily disclose the chemical makeup of their brands. But much more specific information and research about the manufacturing process is needed. As an example of the harm caused when industry testing is inadequate, in 1996 Patrick Schlievert's lab demonstrated that pluronic L92, the normally nontoxic substance used for the outer coating of Rely tampons, could dramatically magnify the amount of toxin produced by the TSS-strain of bacteria (Schlievert et al. 2010).

Other flaws in the oversight process may also be at play. Since 1980, new tampon products must be reviewed by the FDA and demonstrate equivalency in safety and effectiveness with those already on the market. The review process, known as premarket approval (PMA), requires results of testing on the safety of all materials in tampons and applicators; tampon absorbency, strength, and integrity; and whether tampons alter the growth of both normal and harmful bacteria in the vagina. Once approved, any changes affecting the safety or effectiveness of tampons must be reviewed via a PMA supplement. Such changes include those made to the indication 
for use; facilities to manufacture, process, or package the device; and sterilization procedures, labeling, and packaging. Perhaps most noteworthy in these regulations is the leeway manufacturers are afforded in the oversight of product modifications. It rests on PMA holders to determine whether changes in safety or effectiveness are substantial enough to trigger a supplemental government review (C.F.R. $\$ 814.20)$. To what extent this practice has led to suboptimal oversight of manufacturing and marketing practices remains unclear. Not surprisingly, the FDA webpage which describes this process to consumers is silent on these omissions in regulatory oversight (http://www.fda/gov/ForConsumerUpdates/ ucm612029.htm).

\section{Industry Practices: Behind Closed Doors}

While government standards for testing tampon safety and defining ingredients have stagnated, tampon producers seeking a competitive edge on their rivals have introduced innovations in tampon testing methods, ingredients, and manufacturing, as evidenced by a review of patents, industry websites, medical literature, and court cases. For example, in 1999 Kimberly-Clark was granted a patent for the invention of an "artificial menses fluid," which they hoped would provide a safer, more cost-effective menses substitute to better emulate real menstrual blood (Achter et al. 1999). The simplicity of their patent was stunning: a recipe of defibrinated blood (ranging from 10-60\%) and egg white $(20-60 \%)$. Although the conditions of the application stated that human blood could be used, the patent authors cited concerns that using it would expose researchers to viruses or diseases (column 1, line 21). Instead, the inventors proposed swine blood from the slaughterhouse (no diseases there!).

Producers frequently shift the composition of ingredients in their tampons, which makes gaps in standards on the disclosure of menstrual product ingredients particularly troubling. Most producers readily acknowledge that tampons in the US are usually made of nonorganic cotton, rayon, or a combination of these materials. However, they seldom disclose exact proportions or the cost motivations and implications of these choices. Viscose rayon (a semisynthetic fiber) is highly absorbent and very cheap, making it preferable to cotton for boosting profits (Kumeh 2010). Moreover, the proportion of cotton to synthetics within tampons is known to vary with the price of cotton (Rosenthal 2019). Thus, because manufacturers are not required to disclose the ingredients, such dynamic lot-to-lot variations are not likely to be viewed as substantial enough to be reported to the FDA. It is unknown whether these differences in the ratio of materials alter product performance or chemical exposures, but they demonstrate another reason why more transparency is needed. 
Tampon producers are also forging into the "green" product market. Perhaps the most striking example of this is P\&G's acquisition in early 2019 of the small US company L., makers of organic period products (tampons and pads) advertised as, "free of pesticides, chlorine, fragrances or dyes" (https://thisisl.com). It is anyone's guess to what extent P\&G's new-found commitment to all natural products is a strategy to counter concerns about by-products formed in the bleaching processes used to make their nonorganic cotton products, like Tampax Pure and Clean. Alternatively, it could represent recognition that consumer products with natural ingredients make up the fastest growing segment in the industry (Meyersohn 2019). In any case, by acquiring a leader in the Femtech industry, corporate America has now become fully immersed in the "go green" movement.

\section{mTSS in the Twenty-First Century: New Products, New Worries, and Gaps in Research}

Today, some 30 years after the mTSS epidemic, one might presume there is little cause to pursue tampon safety in regards to regulation, production, and research. Indeed, as shown in Fig. 51.3, there was a direct correlation between the dramatic decline in TSS cases and the FDA actions relating to tampon absorbency over the 1980s.

Yet, despite the very low incidence of contemporary mTSS ( $1-17$ cases/yr; Code of Federal Regulations 2017), the disease remains of compelling interest for several reasons: the widespread use of tampons in the Global North;

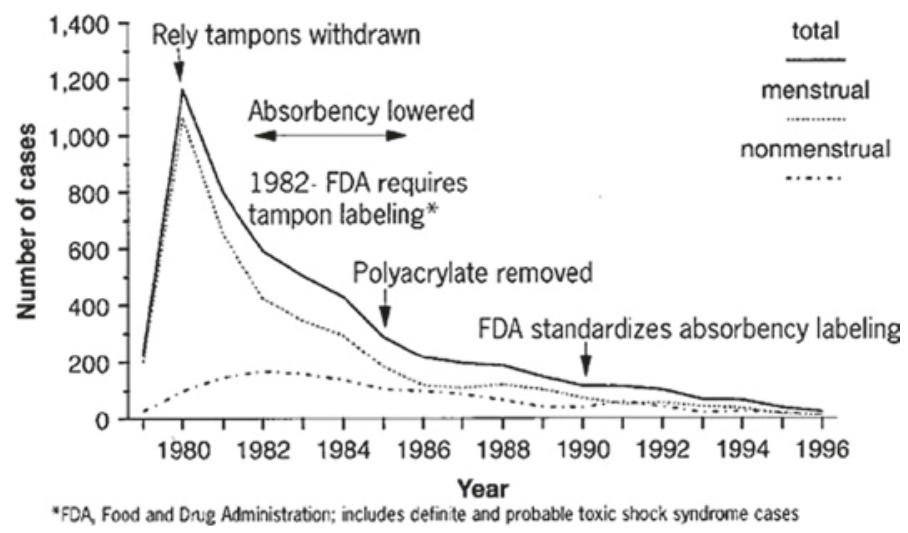

Fig. 51.3 Profile of the decline in both TSS cases and tampon absorbency, 19801996 from the CDC website. Accessed July 26, 2019 at https://wwwnc.cdc.gov/ eid/article/5/6/99-0611-fl (Original source Hajjeh RA et al. Toxic Shock Syndrome in the United States: Surveillance Update, 1979-1996. Emerging Infectious Diseases Vol. 5, No. 6, November-December 1999, page 807. Credit: The US Center for Disease Control 1999) 
growing evidence that menstrual cups may also pose risks (Mitchell et al. 2015; Sharma et al. 2018; Jacquemond et al. 2018; van Eijk et al. 2019); and mounting concern that methicillin-resistant staphylococcal aureus (MRSA) organisms pose a new threat (Sada et al. 2017; Sharma et al. 2018).

What is especially troubling is that the underlying epidemiology of TSS remains equivocal. Despite the industry-wide reduction of tampon absorbency, cases of mTSS persist, with occasional flare-ups in state-wide reports (Cowart 2016). In early 2016, five cases of mTSS in Michigan were reported to the CDC in a span of four months, far outpacing the usual number of cases nationwide in any one year (24 cases in 2017; CDC 2017; Eisner 2016). In Europe, where mTSS is not a "notifiable illness" to the health authorities, health professionals have warned that the number of cases today may be much higher than 15 cases per year, due to misdiagnoses or "near-misses" in meeting the number of diagnostic criteria. ${ }^{6}$ Even in the US, it is argued that the use of overly stringent diagnostic criteria may be substantially underestimating the total TSS burden (DeVries et al. 2011). Despite these concerns, researchers have yet to definitively clarify the risk factors associated with the disease.

Several labs over the years have found evidence which debunks the long-standing notion that lower absorbency brands and all-cotton products might be safer or provide greater protection from TSS (Spaulding et al. 2013). Most recently this idea was challenged by findings from a French laboratory study which demonstrated that both the TSS-linked bacteria as well as its deadly toxin could be easily grown on tampon fibers across all brands and absorbencies as well as in menstrual cup materials. The investigators concluded that menstrual cups may be even riskier due to their shape and volume, which may allow more oxygen to enter, transforming the anaerobic environment to an aerobic one in which the bacteria can thrive (Nonfoux et al. 2018). Moreover, because a bacterial biofilm adheres readily to the cup's surface, the investigators recommended that they be sterilized between uses, rather than just washed with soap and water. In contrast, epidemiologic evidence suggests menstrual cups may not impose any more risk than tampons, while having a high level of acceptance as an affordable, single-use product in both high- and low-income countries. A recent meta-analysis by van Eijk and colleagues (2019) of 43 studies involving more than 3000 participants in 99 countries concluded that menstrual cups "seem to be an effective and safe alternative to other menstrual products," although more research is needed.

The CDC has also recently expressed doubts about some of their original data. During the TSS epidemic, they conducted telephone interviews with verified TSS patients and with control cases to compare sensitive information about menses management, including duration of tampon wear (Shands et al. 2017). Unsurprisingly, when assessed this way, there were no differences by study group. One CDC panelist confirmed that, "we don't know if more 
frequent changing reduces risk (of mTSS) . . . there was never any science done to support this recommendation" (Shands et al. 2017). Despite this, the FDA considered it prudent to include in TSS label warnings the advice to avoid wearing tampons for longer than 8 hours.

Such uncertainties and gaps in research may have disproportionately higher impacts on younger women and adolescent girls (Shands et al. 1980). It is now believed mTSS is triggered by the overgrowth of bacteria (Staphylococcus aureus) capable of producing toxins in the presence of the menses usually retained in a tampon, particularly in young individuals who lack adequate antibodies to mount a sufficient immune response (Spaulding et al. 2013). At the same time, one study found that relevant antibody levels in adolescent girls as young as age 12 were already elevated to adult levels, implying that they should be well protected (Parsonnet et al. 2005). Nonetheless, the average age of mTSS in the UK is 19 (Sharma et al. 2018), some $40 \%$ of mTSS cases in the US occur in 13-19 year-olds (Hajjeh et al. 1999), and a hospital-based medical record review suggested that the rates of TSS in adolescents is rising (Brite and Cope 2004).

It is unclear to what extent other demographic factors, such as race and ethnicity, contribute to the risk of contracting TSS. This means women of color are another group unduly affected by gaps in research on period product safety (Parsonnet et al. 2005). There is some evidence which suggests Black women may be less likely to mount an adequate antibody response to the toxin (Parsonnet et al. 2005), however, most US studies involve inadequate numbers of women of color. The well-documented ethnic and cultural differences in menstrual management practices (Finkelstein and Von Eye 1990), coupled with emerging evidence for ethnic differences in the vaginal environment and disease rates (for example, vaginitis), further add to the need for more diverse study populations (Nicole 2014).

As mTSS persists, the evidence gathered from independent researchers linking the broader spectrum of period products to its etiology is steadily mounting (Fig. 51.4). Add to this an array of emerging vaginal products that expand the definition of "tampon," including disposable tampons for urinary bladder leakage, medicated tampons for menstrual cramp relief, and tampons containing capsules for incubation of sperm and egg for intravaginal fertilization (Reame 2018). Without careful scrutiny of these and other new vaginal products, one must ask the question: Is this the next biotechnology accident waiting to happen? It is hard to tell.

Because of the rare nature of mTSS, research on the illness is especially difficult to undertake, is largely supported by industry when conducted, and is limited to cross-sectional designs that give just snapshot impressions of the vaginal milieu. Moreover, there have been no additional case-controlled, epidemiologic follow-up studies in TSS victims, or laboratory-based, cross-brand comparisons undertaken by federal agencies to provide ongoing assessments of the absorbency performance of contemporary products (Shands et al. 2017). 


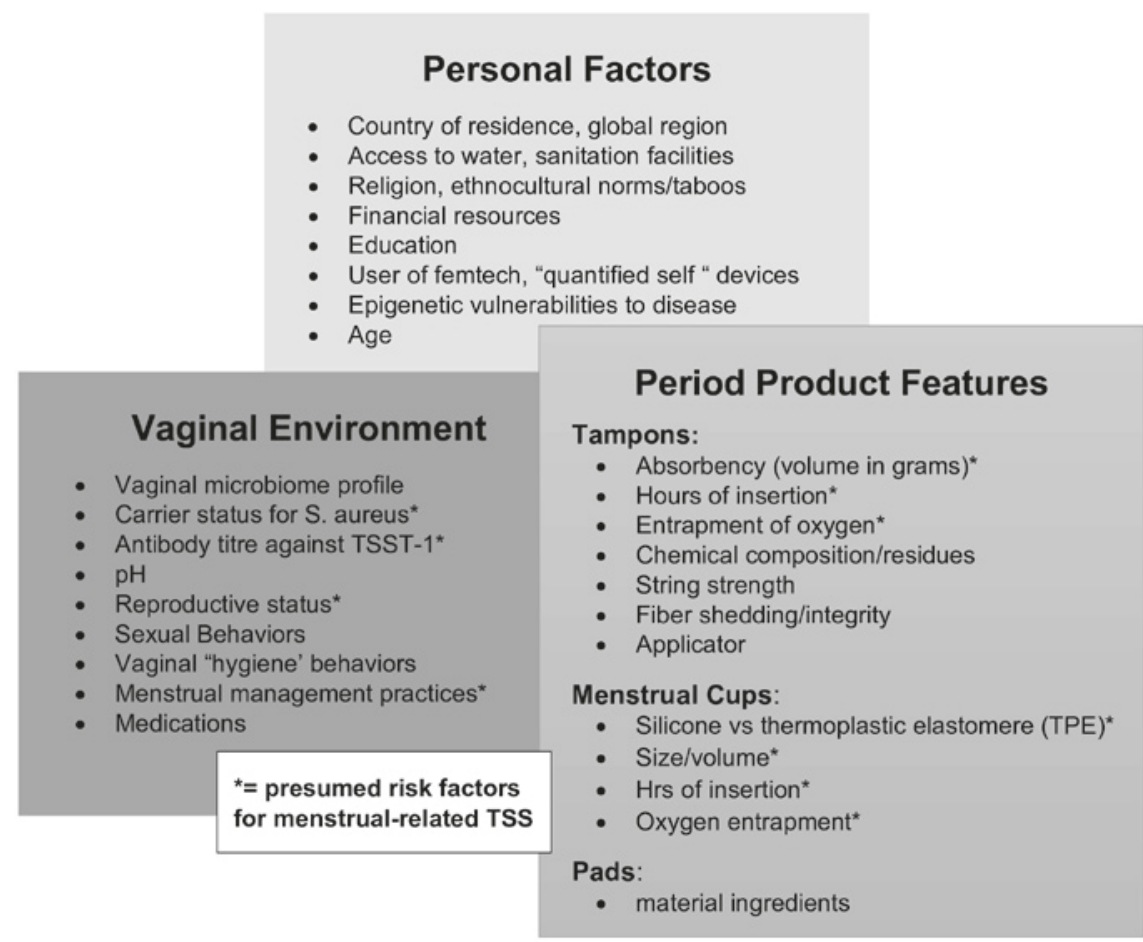

Fig. 51.4 Factors influencing the vaginal microbiome and menstrual health (Source Content summarized from Schlievert et al. (2010), Spaulding et al. (2013), Davis et al. (2014), Jacquemond et al. (2018), Nonfoux et al. (2018). Credit: Nancy Reame)

The present state of assessment protocols, regulatory oversight, and common practices in the tampon industry are unlikely to change this any time soon. Thus, should a future mTSS outbreak occur, federal agencies may not be equipped to help consumers understand the risk profiles of new products. Encouragingly, the contemporary atmosphere of menstrual health advocacy offers unprecedented opportunity to change that.

\section{Using Menstrual Activism to Define the Research 'Vagenda" in Menstrual Health}

In a 2018 commentary, I reflected on the lessons learned through efforts to draw broader attention to the public health campaigns which sought improved tampon testing and safety standards in the 1980s. I noted that, " [e]mbedded in a culture of menstrual stigma, and without the benefit of 
podcasts, tweets, blogs, and other social media amplifiers, these efforts were unable to gain the kind of traction needed to keep the message in front of the public. We were clearly ahead of our time" (Reame 2018, 252). Fortunately, these are just some of the many tools that menstrual health advocates have in their arsenals today.

Just as the Boston Women's Health Book Collective and other consumer groups were during the mTSS crisis, menstrual activists today are at work as citizen scientists. In addition to savvy social media skills, they draw on medicolegal training to generate their own data, scrutinize consumer complaints, and monitor symptoms as a way to influence social change. ${ }^{8}$ Moreover, with the help of Big Data technologies, advances in precision medicine, massive biobanks, and mobile phone tracking applications, we have clearly reached a tipping point when research gaps in the lived experience of menstruators and their menstrual health can be addressed in more rapid, meaningful, and productive ways.

An important lesson from the mTSS tragedy of the 1980s was the recognition by the US federal government of consumer groups as legitimate expert partners. In many disease areas, the involvement of the consumer/patient as expert has transformed how government-sponsored biomedical research is carried out. Examples, such as the web-based Patients Like Me project, reflect this important new respect for patients as equal partners in the research enterprise. Indeed, one private research institute with a major focus on women and children, the PatientCentered Outcomes Research Institute (PCORI), even requires involvement by patients and other stakeholders across all stages of the research process and mandates the use of patient-driven outcomes (www.pcori.org). Such an approach is clearly overdue for menstrual health research. An encouraging sign of interest by the federal government came in 2018 with the NIH invitational conference on menstruation science, which covered an array of promising new discoveries in 'omic' analysis of the endometrium, new sampling or imaging modalities, smart technologies/apps and mHealth platforms, and health literacy and dissemination frameworks (https://www.ncbi.nlm.nih.gov/pmc/articles/PMC5782905/).

Despite these collective sociopolitical forces, I would argue that the need for continuing vigilance and improved tampon safety protections is as great as ever, perhaps even more so, given the current anti-woman, anti-environment political environment. With that in mind, I offer below some suggestions for ways that the activists in this "second menstrual moment" can partner with the federal research enterprise to improve the research 'vagenda' in menstrual health (updated from Reame 2018). US health policies and regulations governing the safety of menstrual hygiene products remain relatively unchanged, despite the fact that the precise mechanism for tampon-related TSS is still debated, superabsorbent products continue to be introduced, and occasional spikes in TSS cases occur. The 2018 NIH Conference held on Menstrual Science was an encouraging first step, taken partially in response to a worldwide call to action by grassroots organizations to focus on the long-ignored menstrual health agenda so in need of attention. 


\section{Recommendations to Improve the Research 'Vagenda' in Menstrual Health Care and Period Product Safety}

1. Tell legislators it is time to pass H.R. 3865, the Robin Danielson Feminine Hygiene Product Safety Act (116th US Cong. 2019), with language that includes menstrual cups and bladder support products in all testing and research requirements (absorbency, chemical composition, string strength, fiber shedding, and tampon integrity).

2. Demand through the Freedom of Information Act that the FDA release its PMAs for new inventions that were subsequently approved, as well as any post-marketing data on health and safety problems reported to the CDC by product brand and absorbency.

3. Petition relevant NIH Institutes and Offices (for example, National Institute of Child Health and Human Services, Office of Research on Women's Health) to partner with the CDC and FDA to make tampon safety a priority for future strategic plans for women's health research.

4. Petition federal government research agencies (for example, National Institute of Environmental Health Sciences, National Cancer Institute) to undertake studies of the vaginal microbiome and characterize menstrual fluid as has been done with saliva for its potential as an exposome biomarker of health (Bessonneau, Pawliszyn, and Rappaport 2017).

5. Petition the NIH to fund studies that use Big Data approaches to study race/ethnicity variation in the interactions between vaginal health practices, the vaginal microbiome, and mTSS by taking advantage of the evolving million-patient database and biorepository of the NIH "All of Us" research initiative (https://allofus.nih.gov).

6. Capitalize on the menstrual health movement to lead a public health campaign to "Make the Menstrual Cycle a Vital Sign." Partner with relevant medical, nursing, and health care organizations (for example, the American College of Obstetricians-Gynecologists, the Society for Women's Health Research) to develop practice guidelines for making the menstrual cycle a vital sign across the reproductive life span. The current ACOG guidelines, for example, are silent on risk factors for mTSS in women and girls, and say nothing about menopause-related health impacts. ${ }^{9}$

\section{Notes}

1. Proctor \& Gamble's superabsorbent, all-synthetic product Rely proved to be the most lethal and was quickly taken off the market.

2. Sharra Vostral has written extensively about these events (Vostral 2017a).

3. In agreement with Epstein and colleagues (2017), I use the term "woman" here to refer to anyone who has ever experienced a menstrual cycle. At the same time, I acknowledge that not all individuals who have a menstrual cycle identify as a woman, and not all those who identify as a woman have a menstrual cycle.

4. Pediatric Endocrine Lab staff members: Maura Baun, Katherine Kersey; Nursing masters' students, Ruth Lewis, Susan DeLonis. 
5. The Robin Danielson Feminine Hygiene Product Safety Act of 2019, H.R. 3865 , remains in committee at the time of this writing.

6. The Toxic Shock Syndrome Information Service (TSSIS) is a UK organisation funded and supported by Lil-Lets UK Ltd., Johnson \& Johnson Consumer Services EAME Ltd., Kimberly-Clark Ltd., Ontex Retail Ltd., Procter \& Gamble UK and Toiletry Sales Ltd. www.toxicshock.com/tssfacts/.

7. I attribute the word "vagenda" to comedienne Amanda Seales, who used this in her HBO special "I Be Knowin'” (2019) in reference to her vagina's agenda.

8. For example, see the ChemFatale report by the Women's Voices for the Environment (www.womensvoices.org/feminine-care-products/whats-in-yourtampon/).

9. During 2018 and 2019, while writing this chapter, Dr. Reame served as a paid consultant to Diva International, Inc. (makers of the Diva menstrual cup), unpaid advisor to the menstrual tracking app Clue, the blog WomenLivingBetter, and the Femtech company DropletHealth. In the 1980s, Dr. Reame served as the independent laboratory for the consumer representatives on the FDA Task Force that tested tampon absorbency and set labeling requirements for the US tampon industry. She also serves as an advisor to the women's health advocacy organization, Our Bodies, Ourselves. Part of this commentary originally appeared in the keynote paper, "A Research Program on the Menstrual Cycle: Looking Back, Moving Forward" presented at the 2017 meeting of the Society for Menstrual Cycle Research. Other sections were adapted from "The Legacy of Tampon-Related Toxic Shock Syndrome: Feats, Failures, and Future Challenges for Women's Health Scholars" (Reame 2018).

\section{REFERENCES}

Achter, et al. 1999. Artificial Menses Fluid. US Patent 5,883,231, filed August 21, 1991 and issued March 16, 1999.

Bessonneau, Vincent, Janusz Pawliszyn, Stephen M. Rappaport. 2017. “The Saliva Exposome for Monitoring of Individuals' Health Trajectories." Environmental Health Perspectives 125 (7): 077014.

Bobel, C. 2018. "Menstrual Pads Can’t Fix Prejudice.” The New York Times. https:// www.nytimes.com/2018/03/31/opinion/sunday/menstrual-periods-prejudice. html.

Brite, R. A., and J. U. Cope. 2004. "Tampon-Related Toxic Shock Syndrome (TSS) Continues to Peak among Adolescent Girls: A Nationwide Hospital Study.” Journal of Pediatric and Adolescent Gynecology 17 (3): 222.

Centers for Disease Control and Prevention. 2017. Morbidity and Mortality Weekly Report (MMWR). https://www.cdc.gov/mmwr/volumes/66/wr/mm6652md. htm.

Code of Federal Regulations. 2017. Title 21, Volume 8, Sec. 801.430, April 1, 2017. "User Labeling for Menstrual Tampons."

Cowart, L. 2016. "Women Are Still Getting Toxic Shock Syndrome and No One Knows Why." Washington Post, March 21, 2016. https://www.washingtonpost. $\mathrm{com} /$ news/speaking-of-science/wp/2016/03/21/women-are-still-getting-toxicshock-syndrome-and-no-one-quite-knows-why/?noredirect $=$ on.

Davis, C. C., M. Baccam, M. J. Mantz, T. W. Osborn, et al. 2014. "Use of Porcine Vaginal Tissue Ex-Vivo to Model Environmental Effects on Vaginal Mucosa to 
Toxic Shock Syndrome Toxin-1." Toxicology and Applied Pharmacology 274 (2): 240-48.

DeVries, A. S., L. Leshe, P. M. Schlievert, et al. 2011. "Staphylococcal Toxic Shock Syndrome 2000-2006: Epidemiology, Clinical Features, and Molecular Characteristics." PLoS One 6 (8): e22997.

Eisner, Jennifer. 2016. "Michigan Confirms Increase in Toxic Shock Syndrome Cases." Michigan Department of Health and Human Services. https://www.michigan.gov/mdhhs/0,5885,7-339--378024--,00.html.

Epstein, Daniel A., Nicole B. Lee, Jennifer H. Kang, Elena Agapie, Jessica Schroeder, Laura R. Pina, James Fogarty, Julie A. Kientz, and Sean Munson. 2017. "Examining Menstrual Tracking to Inform the Design of Personal Informatics Tools." Proceedings of the 2017 CHI Conference on Human Factors in Computing Systems, 6876-6888.

Finkelstein, J. W., and A. Von Eye. 1990. "Sanitary Product Use by White, Black and Mexican American Women." Public Health Reports 105: 491-96.

Hajjeh, A., A. Reingold, A. Weil, K. Shutt, A. Schuchat, and B. A. Perkins. 1999. "Toxic Shock Syndrome in the United States: Surveillance Update, 1979-1996." Emerging Infectious Diseases 5 (6): 807-10.

Jacquemond, J., A. Muggeo, G. Lamblin, A. Tristan, Y. Gillet, P. A. Bolze, et al. 2018. "Complex Ecological Interactions of Staphylococcus Aureus in Tampons during Menstruation." Scientific Reports 8: 9942.

Kumeh, T. 2010. "What's Really in That Tampon?" Mother Jones. https://www. motherjones.com/politics/2010/10/whats-really-tampon-and-pad/.

Meyersohn, Nathaniel. 2019. "Procter \& Gamble Buys Organic Tampon Brand L.” CNN, February 5, 2019. https://www.cnn.com/business/live-news/ stock-market-news-today-020519/h_5036bff9491116ae94555c198bbfc2a0.

Mitchell, M., S. Bisch, S. Arntfield, and S. Hosseini-Moghaddam. 2015. "A Confirmed Case of Toxic Shock Syndrome Associated with Use of a Menstrual Cup." Canadian Journal of Infectious Diseases and Medical Microbiology 26: 218-20.

Nicole, W. 2014. "A Question for Women's Health: Chemicals in Feminine Hygiene Products and Personal Lubricants." Environmental Health Perspectives 122 (3): A70-A75.

Nonfoux, L., M. Chiauzzi, C. Badiou, et al. 2018. "Impact of Currently Marketed Tampons and Menstrual Cups on Staphylococcus Aureus Growth and TSST-1 Production In Vitro." Applied and Environmental Microbiology 84 (12): e00351-18.

Parsonnet, J., et al. 2005. "Prevalence of Toxic Shock Syndrome Toxin 1-Producing Staphylococcus aureus and the Presence of Antibodies to This Superantigen in Menstruating Women." Journal of Clinical Microbiology 43: 4628-34.

Reame, Nancy. 1983. Nancy Reame to David Swankin, with Attached Report. Boston Women's Health Book Collective, Folder 34, Box 1. Cambridge, MA: Radcliffe Institute for Advanced Study Harvard University-Schlesinger Library, May 23, 1983.

Reame, Nancy. 2018. "The Legacy of Tampon-Related Toxic Shock Syndrome: Feats, Failures, and Future Challenges for Women's Health Scholars." Women's Reproductive Health 5 (4): 250-61. https://doi.org/10.1080/23293691.2018.1 523118. 
Reame, N. E., S. Delonis, and R. Lewis. 1987. "Menstrual Tampons: Changes in Absorbency and Styles since 1982." In Seventh Conference of the Society for Menstrual Cycle Research, University of Michigan, Ann Arbor, June 1987.

Reingold, A. L., N. T. Hargrett, K. N. Shands, et al. 1982. "Toxic Shock Syndrome Surveillance in the United States, 1980 to 1981." Annals of Internal Medicine 96: 875-80.

Rome, E. R., J. Wolhandler, and N. Reame. 1988. "The Absorbency of Tampons." JAMA 259: 685-86.

Rosenthal, Linda. 2019. “Assemblymember Linda B. Rosenthal Announces Passage of First-in-the-Nation Menstrual Product Ingredient Labeling Bill in both Assembly and Senate." News Release, June 21, 2019, Office of NY State Assemblymember Linda B. Rosenthal. Accessed April 23, 2020. https://nyassembly.gov/mem/ Linda-B-Rosenthal/story/87707.

Sada, R., S. Fukuda, and H. Ishimau. 2017. "Toxic Shock Syndrome Due to Community-Acquired Methicillin-Resistant Infection: Two Case Reports and a Literature Review in Japan." ID Cases 8: 77-80.

Schlievert, P. M., K. A. Nemeth, C. C. Davis, M. L. Peterson, and B. E. Jones. 2010. "Staphylococcus Aureus Exotoxins Are Present In Vivo in Tampons. Clinical and Vaccine Immunology 17: 722-27.

Seales, Amanda. 2019. "I Be Knowin.” HBO, January 26, 2019.

Shands, K., A. Reingold, G. Matthews. 2017. Toxic Shock Syndrome: A Lasting Legacy, October 19, 2017, Q\&A response (approx. 1hr 12 mins-1hr 20 mins). https://www.cdc.gov/od/science/wewerethere/toxicshock/.

Shands, K. N., G. P. Schmid, B. B. Dan, D. Blum, R. J. Guidotti, N. T. Hargrett, R. L. Anderson, D. L. Hill, C. V. Broome, J. D. Band, and D. W. Fraser. 1980. "Toxic-Shock Syndrome in Menstruating Women: Association with Tampon Use and Staphylococcus Aureus and Clinical Feature in 52 Cases." The New England Journal of Medicine 303: 1436-42.

Sharma, Hema, Debra Smith, Claire E. Turner, Laurence Game, Bruno Pichon, Russell Hope, Robert Hill, Angela Kearns, and Shiranee Sriskandan. 2018. "Clinical and Molecular Epidemiology of Staphylococcal Toxic Shock Syndrome in the United Kingdom.” Emerging Infectious Diseases 24 (2): 258-266.

Spaulding, A. R., W. A. Salgado-Pabón, P. L. Kohler, A. R. Horswill, D. Y. M. Leung, and P. M. Schlievert. 2013. "Staphylococcal and Streptococcal Superantigen Exotoxins." Clinical Microbiology Reviews 26 (3): 422-47.

van Eijk, A. M., et al. 2019. "Menstrual Cup Use, Leakage, Acceptability, Safety, and Availability: A Systematic Review and Meta-Analysis." Lancet Public Health 4 (8): e376-93. http://dx.doi.org/10.1016/S2468-2667(19)30111-2.

Vostral, S. 2017a. "Toxic Shock Syndrome, Tampons and Laboratory Standard-Setting." CMAJ 189 (20): E726-E728.

- 2017b. "Toxic Shock Syndrome, Tampon Absorbency, and Feminist Science." Catalyst: Feminism, Theory, Technoscience 3 (1). http://dx.doi.org/ $10.28968 /$ cftt.v3il.28788. 
Open Access This chapter is licensed under the terms of the Creative Commons Attribution 4.0 International License (http://creativecommons.org/licenses/ by/4.0/), which permits use, sharing, adaptation, distribution and reproduction in any medium or format, as long as you give appropriate credit to the original author(s) and the source, provide a link to the Creative Commons license and indicate if changes were made.

The images or other third party material in this chapter are included in the chapter's Creative Commons license, unless indicated otherwise in a credit line to the material. If material is not included in the chapter's Creative Commons license and your intended use is not permitted by statutory regulation or exceeds the permitted use, you will need to obtain permission directly from the copyright holder. 